\title{
Deposição e composição química de serrapilheira em um bosque de sabiá
}

\section{Joelma de Lira Freire ${ }^{1}$, José Carlos Batista Dubeux Júnior ${ }^{2}$, Mario de Andrade Lira ${ }^{3}$, Rinaldo Luiz Caraciolo Ferreira ${ }^{4}$, Mércia Virginia Ferreira dos Santos ${ }^{2}$, Erinaldo Viana de Freitas ${ }^{3}$}

\footnotetext{
1 Programa de Pós-graduação em Zootecnia-UFRPE.

2 Departamento de Zootecnia - UFRPE.

${ }^{3}$ Empresa Pernambucana de Pesquisa Agropecuária - IPA.

${ }^{4}$ Departamento de Ciência Florestal - UFRPE.
}

RESUMO - Objetivou-se avaliar a deposição e composição química de componentes da serrapilheira existente e depositada em um bosque de sabiá (Mimosa caesalpiniifolia Benth). O experimento foi realizado durante o período de agosto de 2006 a julho de 2007. A avaliação da serrapilheira existente e depositada foi realizada a cada 28 dias utilizando-se 20 quadrados de $1 \mathrm{~m}^{2}$, alocados aleatoriamente, escolheno novas áreas a cada avaliação. O bosque apresentou plantas com diâmetro média na altura do peito de $26,8 \mathrm{~cm}$. A deposição mensal de matéria orgânica de folhas e ramos no período experimental foi de 15.167 e $3.373 \mathrm{~kg} / \mathrm{ha}$, respectivamente, e aumentou no período de maior precipitação, numa relação de 0,30 com o acúmulo, o indica acúmulo maior que a deposição. A proporção de folhas foi de $87 \%$ do total da serrapilheira, com médias de 2,9\% de nitrogênio e $0,17 \%$ de fósforo. A relação carbono/nitrogênio das folhas ficou abaixo de 30, enquanto a de ramos, entre 30 e 40 , comprovando melhor qualidade das folhas. Durante o período experimental, a deposição de nitrogênio via serrapilheira foi de aproximadamente $462 \mathrm{~kg} / \mathrm{ha}$ e a de fósforo, $30 \mathrm{~kg} / \mathrm{ha}$. A deposição de serrapilheira é essencial para manutenção da fertilidade do solo em bosques de sabiá e contribui para sua conservação e sustentabilidade.

Palavras-chave: ciclagem de nutrientes, decomposição leguminosa arbórea, nitrogênio: fósforo

\section{Litter deposition and chemical composition under a sabiá canopy}

\begin{abstract}
This research aimed to evaluate the deposition and chemical composition of the components of the existing and deposited litter in a sabiá (Mimosa caesalpiniifolia Benth) canopy. The experiment was carried out from August 2006 to July 2007. The evaluation of the existing and deposited litter was performed every 28 days using 20 squares with $1 \mathrm{~m}^{2}$ randomly allocated and new areas were chosen for each evaluation. The canopy showed plants with an average diameter of $26.8 \mathrm{~cm}$ at breast height. Monthly deposition of organic matter of leaves and branches during the experimental period was $15,167 \mathrm{~kg}$ and $3,373 \mathrm{~kg} / \mathrm{ha}$, respectively, and it increased during the highest precipitation period, in a 0.30 relationship with the accumulation, indicating higher accumulation than deposition. Leaf proportion was $87 \%$ of the total litter, with means of $2.9 \%$ of nitrogen and $0.17 \%$ of phosphorus. The carbon/nitrogen ratio of leaves was below 30, while carbon/nitrogen ratio of the branches ranged from 30 to 40, proving a better quality for leaves. During the experimental period, deposition of nitrogen through litter was approximately $462 \mathrm{~kg} / \mathrm{ha}$ and $30 \mathrm{~kg} / \mathrm{ha}$ for phosphorus. Litter deposition is essential for maintenance of soil fertility in a sabiá canopy and it contributes for conservation and sustainability of the canopy.
\end{abstract}

Key Words: decomposition, legume tree, nutrient cycling.

\section{Introdução}

A ciclagem de nutrientes é importante para a manutenção de ecossistemas de floresta em solos de baixa fertilidade natural, como os situados na Amazônia. Uma forma de transferência de nutrientes são as deposições de serrapilheira (Sampaio et al., 2003), que aumentam a eficiência na ciclagem dos nutrientes, permitindo maior produção e sustentabilidade (Monteiro \& Werner, 1997). A serrapilheira constitui a maior fonte de matéria orgânica (Medeiros \&
Almeida, 1993) e no solo ocorre rápida decomposição inicial de material lábil, materiais mais resistentes mais lentamente, em consequência do mecanismo de adsorção, da estabilização de metabólitos e da redução da biomassa no solo (Tauk, 1990).

Entre as espécies que formam serrapilheira, encontra-se a sabiá (Mimosa caesalpiniifolia Benth), uma leguminosa forrageira com flores brancas e sementes pequenas, tolerante a solos ácidos. Tem sido utilizada para produção de estacas no Nordeste (Drumond \& Oliveira, 1989), e recomendada 
como forrageira em sistemas silvipastoris (Drumond, 2000). Na estação seca, esta espécie perde as folhas, evitando que haja excessiva perda de umidade. A queda de folhas, e também de ramos, forma uma camada denominada serrapilheira, a qual acumula-se sobre o solo, formando uma cobertura vegetal morta (Oliveira \& Prisco, 1967, Garcia et al., 1991).

A deposição de serrapilheira reduz 0,003 a 0,3 kg/ha as perdas de nitrogênio por volatilização diária em consequência da desnitrificação (Monteiro \& Werner, 1997). As serrapilheiras, em geral, são compostas de folhas (60 a $80 \%)$, frutos (1 a 15\%) e ramos (12 a 15\%) (Bray \& Gorham, 1964).

Fernandes et al. (2006) demonstraram que, em áreas de floresta de sucessão secundária espontânea, ocorre deposição anual de 149,81 kg N/ha e 3,00 kg P/ha. O bosque de Mimosa caesalpiniifolia foi superior devido à capacidade das leguminosas em fixar $\mathrm{N}_{2}$, depositando 177 kg N/ha.ano; 3,90 kg P/ha.ano. O estudo da deposição e decomposição da serrapilheira em sistemas silvipastoris é de fundamental importância para o entendimento da ciclagem de nutrientes nestes locais (Tiessen et al., 2003).

O objetivo neste trabalho foi avaliar a deposição e os teores de nitrogênio, fósforo e carbono dos componentes (folhas, frutos e ramos) da serrapilheira existente e depositada em um bosque de sabiá, utilizado como componente de um sistema silvipastoril, durante o período de agosto de 2006 a julho de 2007.

\section{Material e Métodos}

O experimento foi realizado na Estação Experimental de Itambé, pertencente ao Instituto Agronômico de Pernambuco - IPA, situada a $7^{\circ} 25^{\prime} 00^{\prime \prime}$ de latitude sul e $35^{\circ} 06^{\prime} 00^{\prime \prime}$ de longitude WGR, com relevo suave ondulado, na zona da mata setentrional, a $96 \mathrm{~km}$ de Recife. O clima é chuvoso, quente e úmido, com verão seco; temperatura média anual de $24^{\circ} \mathrm{C}$, e precipitação média anual de 1.200 mm (Figura 1).

A vegetação é classificada como floresta caducifólia e subcaducifólia (CPRH, 2003). O solo é classificado como argiloso vermelho-amarelo, de acordo com o sistema brasileiro de classificação de solos (Jacomine, 2001). Foi avaliado um povoamento de sabiá com 18 anos de idade, espaçamento de 4,5 m × 4,5 m e área de 0,11 ha, oriundo dos progenitores $\mathrm{F} 4$, advindos de plantas sem acúleos, a partir de matrizes do bosque da Universidade Federal Rural de Pernambuco e de um plantio comercial da estação experimental de Itambé - Pernambuco (Lima et al., 2008). Desde a implantação, o bosque foi manejado de diferentes formas, tendo recebido $200 \mathrm{~g}$ de superfosfato simples e 口indice Pluviométrico Mensal घMédia Histórica 20 anos

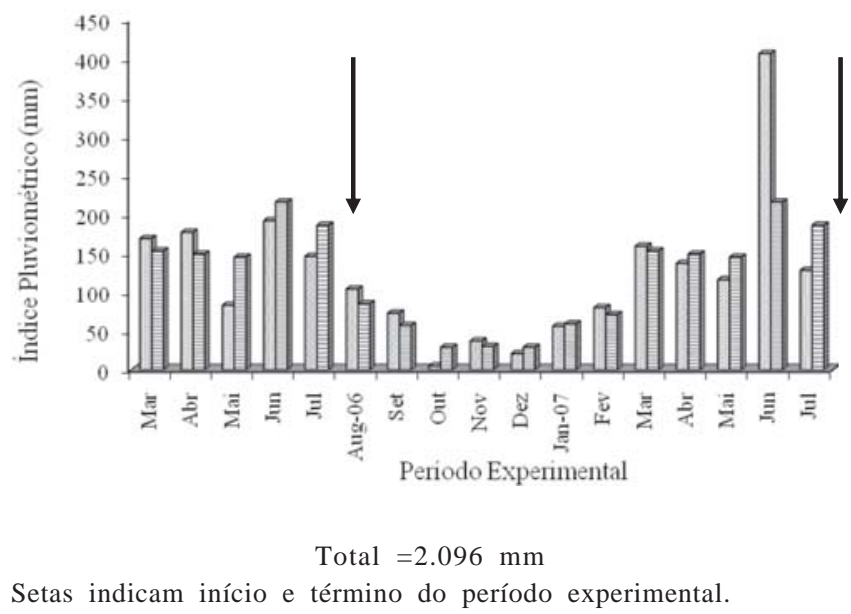

Figura 1 - Precipitação pluvial mensal (mm) durante o período experimental.

esterco de curral curtido no ano de 1995 (Lima et al., 2008), e desramado por bovinos, a fim de avaliar a preferência de plantas com e sem acúleos. No período de agosto a outubro de 1998, para determinação da biomassa, foram coletados 38 fustes de forma proporcional ao tamanho do povoamento. Foram consideradas fustes a porção das árvores compreendidas entre a altura de corte (nível do solo) e as primeiras ramificações na base da copa (Moura et al., 2006).

Amostras compostas do solo do bosque foram realizadas para análise de fertilidade (Tabela 1). As amostras foram retiradas em profundidades de 0-20 e 20-40 cm e as análises realizadas no laboratório de Fertilidade do Solo do Instituto Agronômico de Pernambuco - IPA, segundo metodologia da EMBRAPA (1997).

A avaliação da deposição de serrapilheira de sabiá seguiu metodologia desenvolvida por Bruce \& Ebersohn (1982) e adaptada por Dubeux Jr. et al. (2006a). Para avaliação da serrapilheira existente (acumulada no chão), aquela composta de folhas, frutos e ramos, foram utlitizados 20 quadrados de $1 \mathrm{~m}^{2}$, dispostos aleatoriamente no bosque. Em cada quadrado, a quantidade total de serrapilheira existente no momento da avaliação foi coletada. Após a coleta da serrapilheira existente, foram colocados piquetes

Tabela 1 - Análise do solo da área experimental nas camadas de $0-20$ e de $20-40 \mathrm{~cm}$

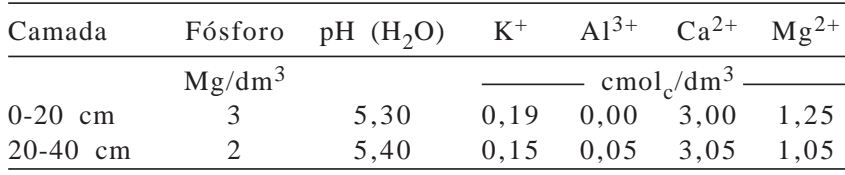

$\mathrm{pH}=$ potencial hidrogênio-iônico; $\mathrm{K}$ = potássio; $\mathrm{Al}=$ alumínio; $\mathrm{Ca}$ = cálcio; $\mathrm{Mg}=$ magnésio. 
de madeira demarcando a área do quadrado e uma lona plástica de aproximadamente $30 \mathrm{~cm}$ de altura, que foi montada no perímetro de cada quadrado com o objetivo de evitar a perda lateral da serrapilheira pela ação do vento. Os quadrados demarcados pelos piquetes tinham por objetivo avaliar a serrapilheira depositada (aquela composta por folhas, frutos e ramos recém-caídos). Ambos os materiais das serrapilheiras existentes e depositadas coletados foram pesados e colocados em sacos de papel devidamente etiquetados e levados à estufa de circulação forçada de ar por 72 horas, a $65^{\circ} \mathrm{C}$. Após essas coletas, 20 novas áreas foram selecionadas para um novo ciclo de determinações de serrapilheira existente e serrapilheira depositada. Essas avaliações foram realizadas a cada 28 dias, no período de agosto de 2006 a julho de 2007, totalizando 12 meses de avaliação. Após a retirada do material colhido da estufa, realizou-se a separação manual dos componentes folhas + frutos e ramos.

A caracterização do bosque foi feita por meio da avaliação da altura das plantas, diâmetro a 1,30 m do solo (altura do peito), diâmetro da base, número de fustes/ touceira e número de ramos/fuste. Para essas medidas foram avaliadas 30 touceiras no bosque, que foram escolhidas a cada $10 \mathrm{~m}$ ao longo de três transectos de $100 \mathrm{~m}$. Essas touceiras foram marcadas e as medições acima indicadas foram feitas sempre nas mesmas touceiras em duas datas: 11/4/2007 e 10/5/2007. Para mensurar a altura da planta utilizou-se régua graduada, que foi posicionada junto ao tronco principal, até o ápice da planta. Para medir o diâmetro da altura do peito, foi utilizado um paquímetro para mensuração. Foram considerados como fustes os troncos principais, enquanto os ramos corresponderam às ramificações encontradas nos fustes.

Foram determinados nas serrapilheiras existentes e depositadas os teores de matéria seca (MS), matéria orgânica (MO), nitrogênio (N) e fósforo (P) de acordo com a metodologia descrita por Silva \& Queiroz (2002), e carbono (C) de acordo com metodologia seguida por Bezerra Neto \& Barreto (2004). As análises foram realizadas no Laboratório de Ração da Empresa Pernambucana de Pesquisa Agropecuária - IPA. A deposição de fósforo (P) e nitrogênio (N) foi calculada a partir dos teores de ambos multiplicados pela deposição da matéria orgânica via folhas e ramos. A deposição de serrapilheira, a quantidade de serrapilheira existente, os teores de nitrogênio e fósforo das serrapilheiras depositadas e existentes foram avaliados através de análise estatística descritiva, calculando-se média e desvio-padrão.

\section{Resultados e Discussão}

Na caracterização do bosque, foram encontrados os seguintes valores: número de fustes/touceira, $3 \pm 1$,6; número de ramos/fustes, $5 \pm 1,1$; altura, 10,50 $\pm 1,0 \mathrm{~m}$; diâmetro na altura do peito (a 1,3 m do solo), 26,8 $\pm 2,21 \mathrm{~cm}$; diâmetro da base, 31,7 $\pm 3,3 \mathrm{~cm}$. Esses resultados são semelhantes aos relatados por Mendes (1989), que observou plantas de sabiá na fase adulta atingindo até $8 \mathrm{~m}$ de altura com $20 \mathrm{~cm}$ de diâmetro na altura do peito e cerca de 3 a 4 fustes/planta. De acordo com esse autor, essas características são importantes para a escolha de genótipos superiores e maior aproveitamento da planta para alimentação, assim como para a produção de estacas de qualidade. Lima (1982) encontrou valores de diâmetro do tronco de 15,6 cm e 21,0 cm em plantas adultas com 7 e 8 anos de idade. Segundo Tigre et al. (1986), para sua utilização silvícola, as matas de sabiazeiro são exploradas geralmente pelo sistema seletivo, no corte de árvores e hastes linheiras bem desenvolvidas.

A deposição mensal de matéria orgânica variou de 404 a $2.311 \mathrm{~kg} / \mathrm{ha}$ (Figura 2). No período de março a julho, ocorreu maior deposição, fato devido à maior pluviosidade.

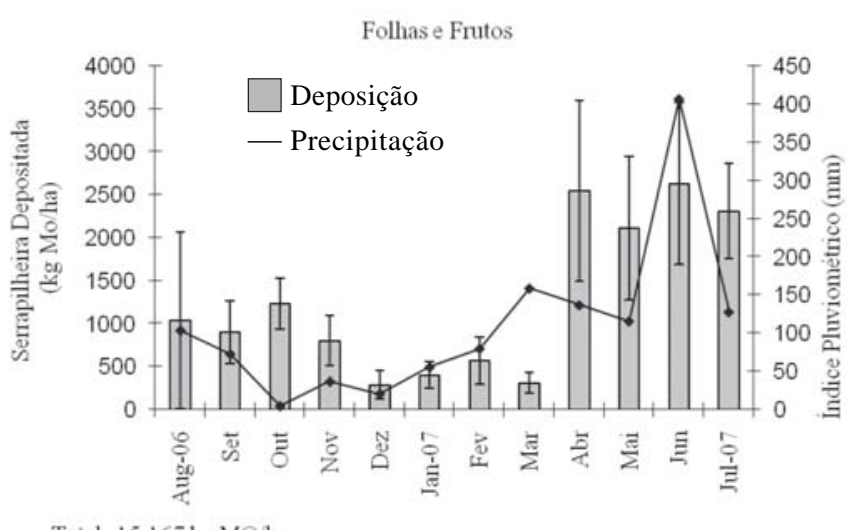

Total $=15.167 \mathrm{~kg} \mathrm{MO} / \mathrm{ha}$

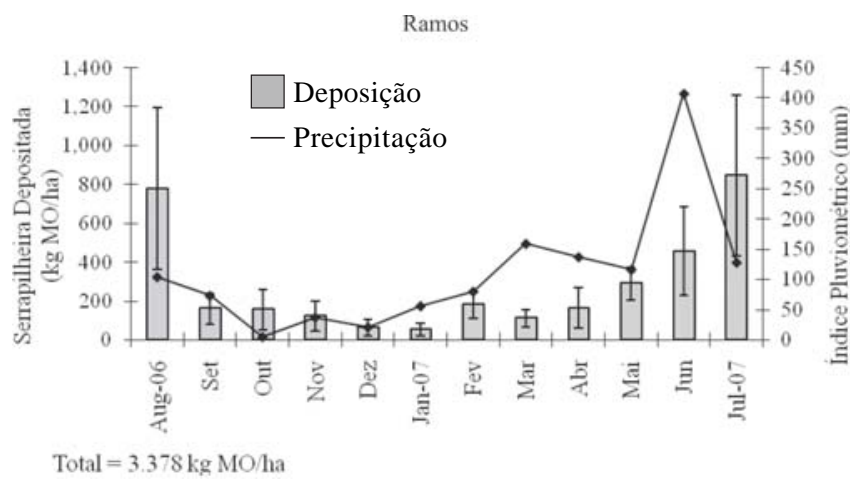

Figura 2 - Deposição de matéria orgânica via folhas, frutos e ramos (kg/ha) e índice pluviométrico (mm) em serrapilheira na área experimental. 
Nesse período, as plantas rebrotaram e, após uma breve estiagem, perderam novamente suas folhas. Segundo Oliveira \& Prisco (1967), durante a estiagem, o sabiá perde as folhas para evitar a excessiva perda de água nesse período. No mês de dezembro ocorreu menor deposição de serrapilheira, sendo o mês de menor índice pluviométrico. Até essa avaliação ocorreu a queda dos resíduos do período seco, e após o inicio das chuvas, a folhagem ressurgiu novamente. Ferreira et al. (2007) encontraram no bosque de sabiá em Itambé, Pernambuco, deposição de 1.624 kg/ha/ mês de serrapilheira no mês de outubro, período em que as plantas perderam suas folhas com o começo da escassez de água, com deposição anual de 7.830 kg/ha de serrapilheira.

A deposição de folhas continua sendo a maior contribuição na deposição de serrapilheira. Os dados encontrados são superiores aos relatados por Virgínio Filho (1995), que afirma que a produção total de fitomassa da folhagem das espécies lenhosas e da parte aérea das herbáceas na caatinga atinge em média 4.000 kg/ha, com grandes variações anuais. Todavia, o bosque ora avaliado encontra-se na Zona da Mata, região diferente da relatada por Virgínio Filho (1995). Além disso, a maior deposição de serrapilheira encontrada neste experimento deve-se provavelmente ao fato de terem ocorrido duas estações chuvosas durante o período experimental de 12 meses, tendo como consequência maior produção de biomassa e, consequentemente, maior deposição de serrapilheira.

A serrapilheira existente (Figura 3) no bosque é função de sua própria deposição e decomposição. Desta forma, o acúmulo de serrapilheira ocorre mais devido à deposição do que à decomposição. Nota-se que ocorreu maior serrapilheira existente nos períodos de chuva, nos meses de março, abril, maio, junho e julho em que as plantas rebrotaram e, logo em seguida, uma breve estiagem ocorreu, resultando na perda de folhas pelas plantas.

As folhas representaram a maior proporção da serrapilheira existente. Nesse sentido, Sampaio et al. (1988) destacaram a sazonalidade influenciando a produção de serrapilheira nas regiões tropicais no ecossistema mata atlântica. A relação entre a deposição e o acúmulo de serrapilheira no último mês de avaliação foi de 0,30 , indicando que houve maior acúmulo do que deposição. A serrapilheira existente em estágio avançado de decomposição apresenta partículas e coloração semelhante ao solo, sendo possível, então, que não tenha sido coletada. Como a matéria orgânica em estágio avançado de decomposição apresenta maior densidade de partícula (Dubeux Jr. et al., 2006b), é possível que a serrapilheira existente tenha sido subestimada. Ferreira et al. (2007), trabalhando em um bosque de sabiá, encontraram acúmulo de serrapilheira existente de
$8.906 \mathrm{~kg} / \mathrm{ha} / \mathrm{ano}$, com relação entre deposição e acúmulo de 0,88/ano; os autores relataram, ainda, que quanto maior o valor dessa relação, mais rápida é a velocidade de decomposição.

As folhas representaram a maior parte do material depositado, apresentando média de 82,9\% (Figura 4). Resultados semelhantes foram encontrados por Ferreira et al. (2007) em bosque de sabiá em Itambé, Pernambuco. Esses autores verificaram que a fração folha representou em média 70,9\% dos resíduos depositados e 65,8\% da serrapilheira acumulada no bosque. Resultados semelhantes foram observados por Sampaio et al. (1988), quando trabalharam na mata de Dois Irmãos. Fernandes et al. (2006) encontraram cerca de $57 \%$ de folhas na composição da serrapilheira em um bosque de sabiá. Os mesmos autores relataram que a fração folha predomina na maioria das avaliações. Proporcionalmente, as folhas representaram a maior parte do material depositado (Figura 4) em detrimento aos ramos, sendo classificada, desta maneira, como serrapilheira fina.

Andrade et al. (2000), em experimento com espécies decíduas em Seropédica, Rio de Janeiro, observaram que o folhedo coletado em área de sabiá (Mimosa caesalpiniifolia Benth) era constituído principalmente por folhas,
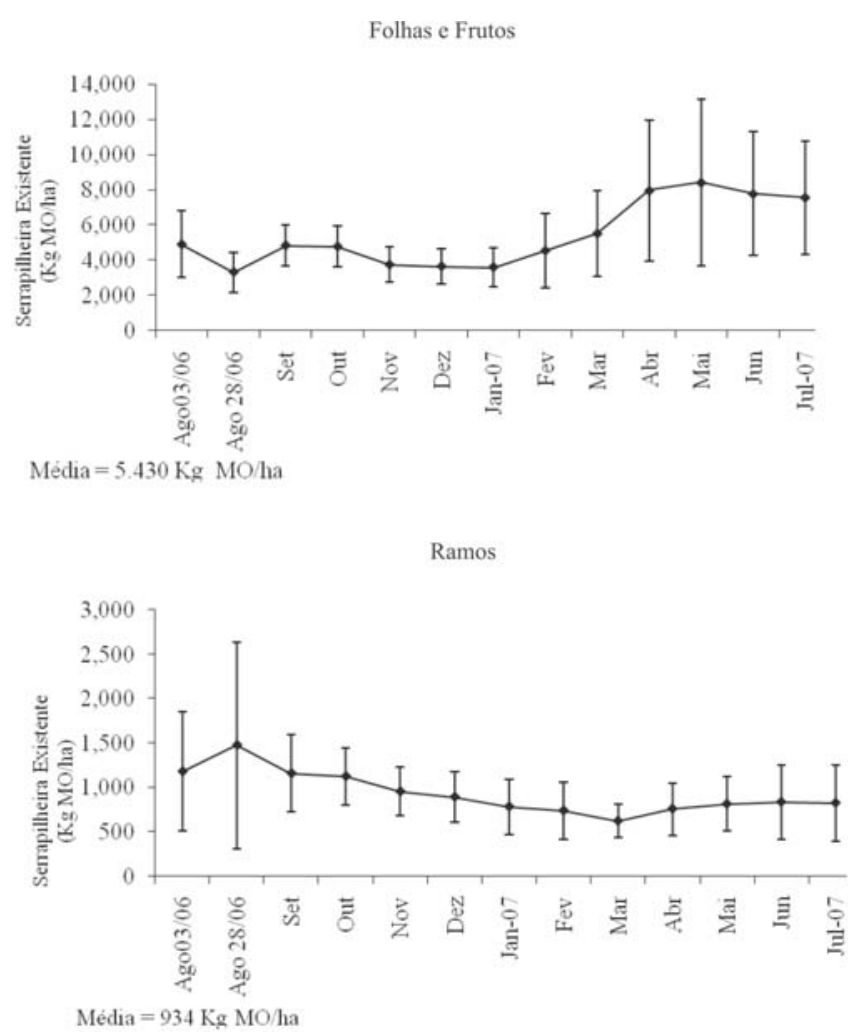

Figura 3 - Folhas, frutos e ramos de serrapilheira existente (kg $\mathrm{MO} / \mathrm{ha}$ ) 
representando de 64 a $70 \%$ do total coletado. Os autores ainda afirmaram que, dependendo da composição e da quantidade de folhedo depositado, ocorrem diferenças no fluxo da matéria orgânica e nutrientes para o solo por meio da decomposição. Essa maior proporção de folhas afeta a reciclagem de nutrientes, já que as folhas apresentam maiores teores de nitrogênio e mineralizam mais rapidamente que os ramos.

Os teores de nitrogênio da serrapilheira depositada (Figura 5) variaram de 2,19 a 3,67\% para folhas e de 1,06 a $1,98 \%$ para ramos. Ferreira et al. (2007) verificaram que as folhas foram os principais contribuintes de nutrientes da serrapilheira, incluindo o nitrogênio na constituição desses nutrientes. Valores semelhantes foram encontrados por Caldas (2007), quando trabalhou na mesma área com partes vivas das plantas, encontrando teores de nitrogênio de $3,5 \%$ no período chuvoso e $2,67 \%$ no período de seca para as folhas; e $1,27 \%$ no período chuvoso e $0,90 \%$ no período de seca para ramos. Dames et al. (2002) reportam que 87\% do nitrogênio presente na parte verde da planta retorna à serrapilheira.

Os teores de nitrogênio tiveram menores oscilações no período da estiagem. Caldas et al. (2009) relataram que as oscilações podem ter decorrido da dificuldade de transporte de nutrientes para a planta em períodos de estiagem, diminuindo o teor de nitrogênio, e que a possível maior contribuição de nitrogênio atmosférico fixado no período chuvoso pode ter contribuído para aumentar o teor observado na parte aérea da planta. Assim, oscilações na parte viva da planta ocasionam mudanças no teor de nutrientes da serrapilheira depositada.

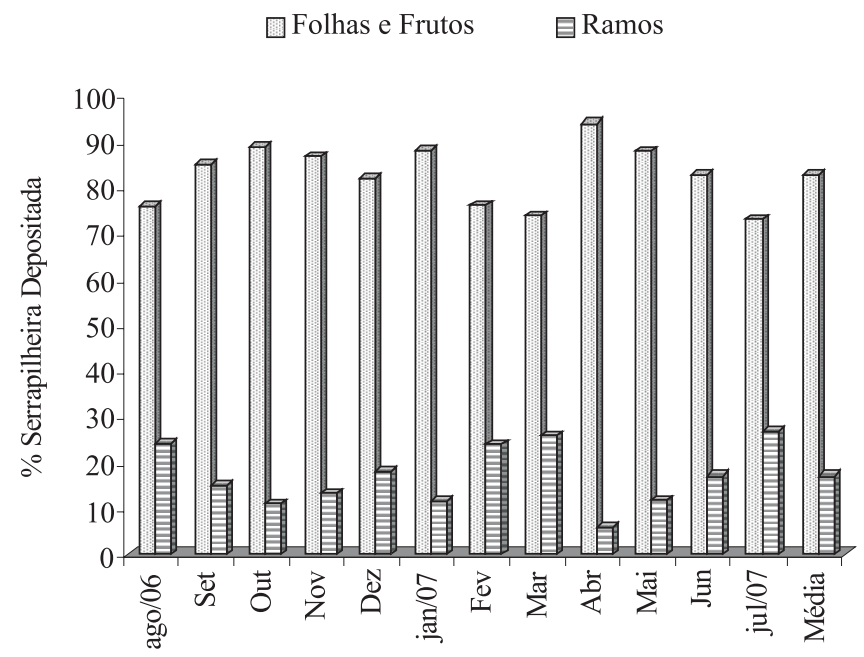

Figura 4 - Proporção de folhas, frutos e ramos de serrapilheira depositada.
Pereira et al. (1997), trabalhando com o "mulch" (cobertura morta) de sabiá, encontraram valores médios de nitrogênio de 2,98\%. Araújo Filho et al. (1990) encontraram valores de nitrogênio na parte área da folhagem verde do sabiá de 3,1\%. Comparando esses valores com os obtidos no presente trabalho, nota-se que os resultados são semelhantes.

O bosque apresentou teor médio de nitrogênio, na serrapilheira existente, de 2,9\% para folhas e 1,7\% para ramos (Figura 5).

Dames et al. (2002), estudando a ciclagem de nutrientes numa plantação de Pinus patula na África do Sul, verificaram que a maior reserva de nitrogênio está no compartimento serrapilheira, sendo aproximadamente 10 vezes maior que no compartimento planta. Segundo os mesmos autores, 48\% do N presente na planta está armazenado nas folhas, e desse estoque, $87 \%$ retorna para a serrapilheira via folha.

Numericamente, o aumento do teor de nitrogênio nos meses de abril, maio, junho e julho ocorreu possivelmente devido à maior pluviosidade nesses meses.

O teor de nitrogênio foi menor nos ramos do que nas folhas, o que evidencia que os ramos são de qualidade inferior e que a fração folha contribui mais com a deposição de nitrogênio via serrapilheira. Segundo Reis \& Barros (1990), os galhos mais grossos têm elevadas relações carbono/nitrogênio, intensificando sua decomposição apenas a partir do $3^{\circ}$ e $4^{\circ}$ ano; assim como as folhas, o conteúdo de nitrogênio desses tecidos é semelhante ao conteúdo no tecido vivo, explicado pelo fato da serrapilheira depositada ser semelhante à existente. Os mesmos autores relatam ainda que a maioria do nitrogênio em solos florestais (> 95\%) encontra-se na forma orgânica e deve ser mineralizado a fim de ficar disponível para a absorção de plantas. Os teores de $\mathrm{P}$ dos ramos foram inferiores aos das folhas (Figura 5), indicando menor qualidade dos mesmos, sendo a folha a maior contribuinte. Além disso, a folha representa a principal proporção de material depositado. Vale destacar, ainda, que mesmo com precipitação maior nos meses de março, abril, maio, junho e julho, os teores permaneceram com valores semelhantes.

Segundo Fassbender (1985), a taxa de deposição desse elemento através da água da chuva é muito pequena. O mesmo autor ainda afirmou que o $\mathrm{P}$ apresenta uma mobilidade bastante baixa na natureza, tornando-se disponível às plantas no ano seguinte à sua deposição. Vale salientar ainda os baixos níveis de P observados na análise de solo, o que pode afetar a concentração deste nutriente na parte aérea da planta.

De acordo com Dames et al. (2002), cerca de 69 a 80\% do fósforo total da planta pode ser reciclado quando esta 
Folhas e Frutos

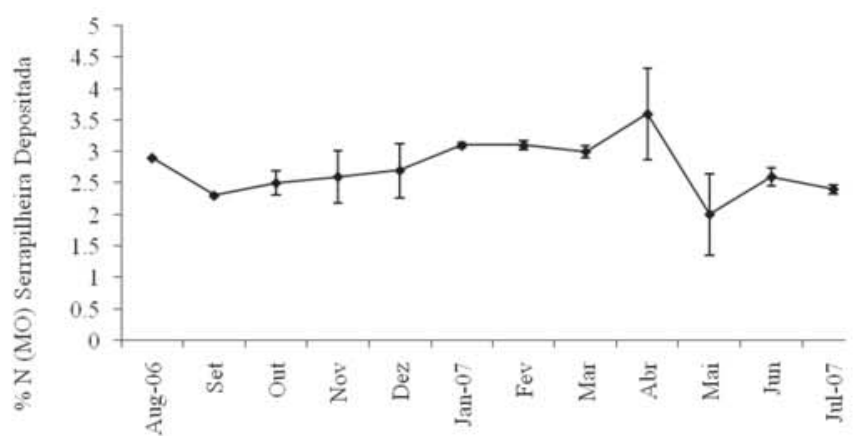

Média $=2,7^{\circ} \mathrm{o}$

Folhas e Frutos

茎

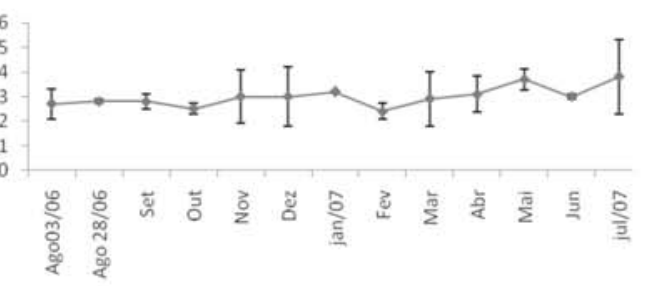

Folhas e Frutos

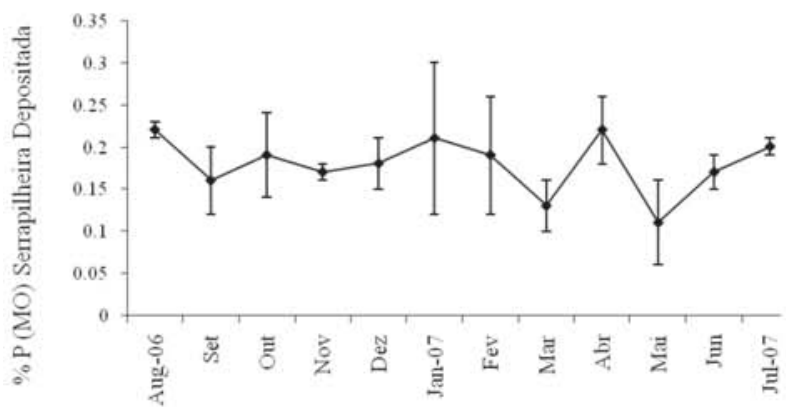

Média $=0,17 \%$

Folhas e Frutos

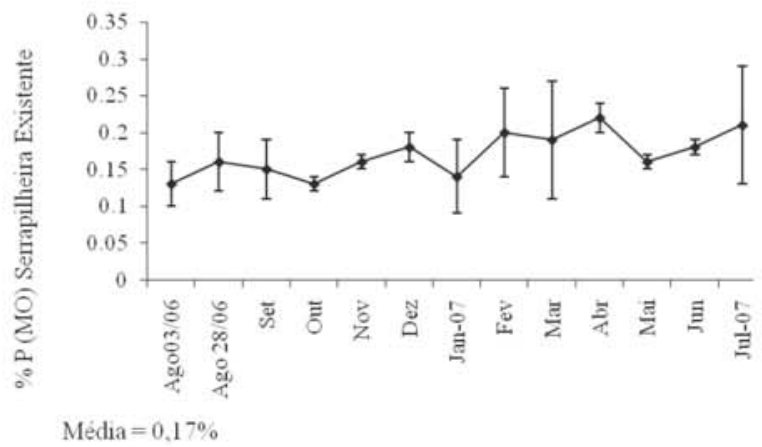

Ramos

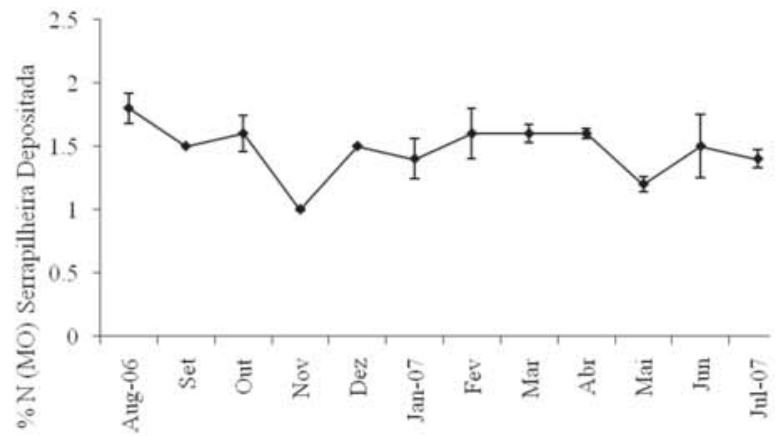

Média $=1.4 \%$

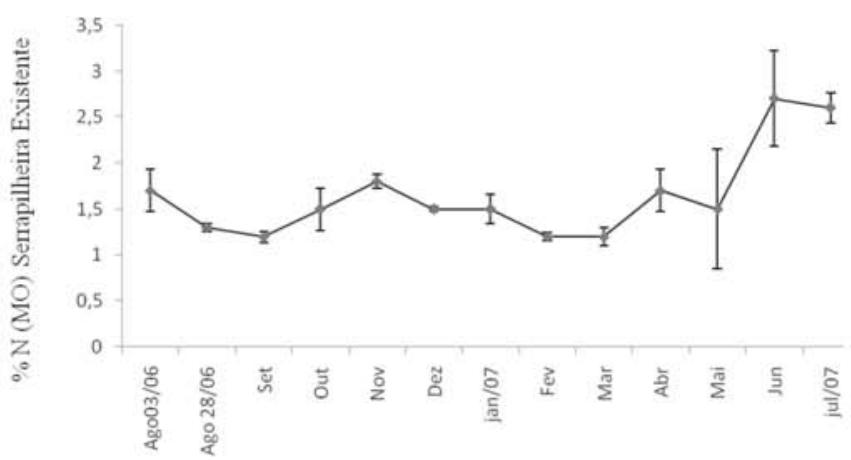

Média $=2,7 \%$

Ramos

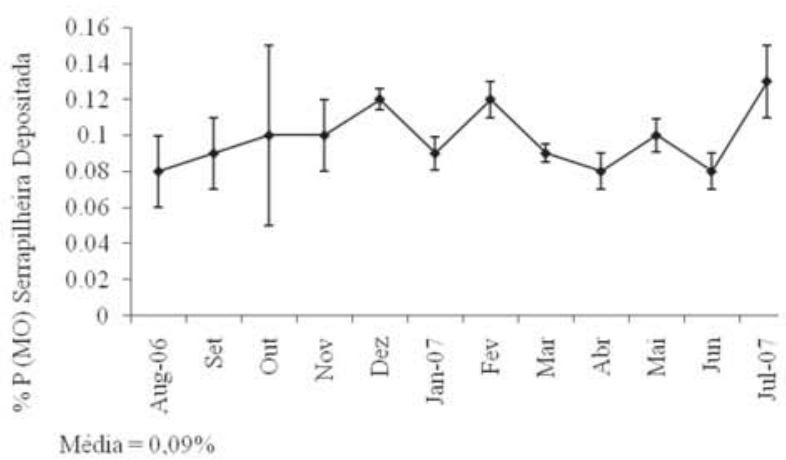

Ramos

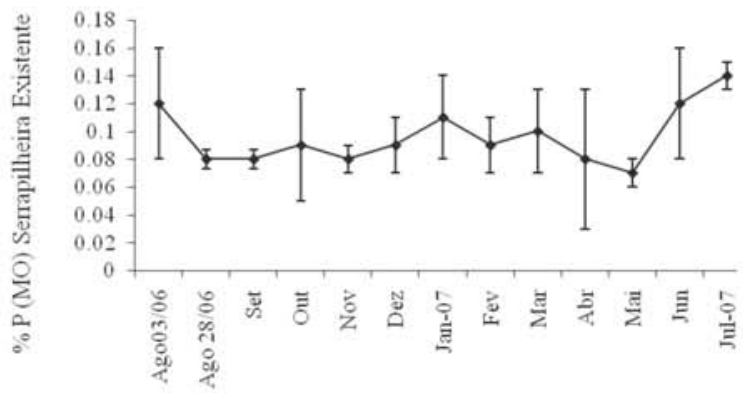

Média $=0.09 \%$

Figura 5 - Teor de nitrogênio e fósforo (\% na matéria orgânica) de folhas, frutos e ramos de serrapilheira depositada e existente.

R. Bras. Zootec., v.39, n.8, p.1650-1658, 2010 
se apresenta em estado latente ou em decomposição. Pereira et al. (1997), estudando a composição química bromatológica do “mulch” e dos fenos de sabiá (Mimosa caesalpiniifolia Benth) obtidos da estação experimental de Itambé-PE, obtiveram valores de 0,06 e $0,17 \%$ de fósforo para o "mulch" e feno, respectivamente. Em geral, o teor de fósforo da serrapilheira existente (Figura 5) foi semelhante ao teor da depositada, com média anual de $0,17 \%$ para ambas.

A deposição de nitrogênio via folhas foi de $408,5 \mathrm{~kg}$ N/ha em um ano de avaliação (Figura 6). Ferreira et al. (2007) encontraram deposição de nitrogênio no mesmo bosque de sabiá de $156 \mathrm{~kg} / \mathrm{ha} / \mathrm{ano}$. Essa quantidade significativa de nitrogênio retornada via serrapilheira é advinda não apenas da fixação biológica de nitrogênio, mas também do nitrogênio reciclado e reabsorvido pela planta. É provável que essa diferença de deposição entre os dois trabalhos acima mencionados seja consequência da precipitação pluvial e de sua distribuição, que ocorreu no período do experimento. Neste trabalho, ocorreram duas estações chuvosas no período de 12 meses. Apesar de apresentarem menor qualidade, os ramos constituem fração significativa no fornecimento de nitrogênio para as plantas. Como nos últimos meses da avaliação houve maior precipitação pluvial, a deposição de nitrogênio também aumentou, devido ao maior volume de deposição de serrapilheira.

Ledgard \& Steele (1992)relataram que a quantidade de nitrogênio fixada por leguminosas varia com estações do ano, adubação nitrogenada e espécie forrageira. Os mesmos autores postulam que, em pastagens com leguminosas, a fixação variou entre 13 a $682 \mathrm{~kg} \mathrm{~N} / \mathrm{ha} / \mathrm{ano}$.

A deposição de fósforo (Figura 6) aumentou também no período chuvoso, devido à maior deposição de serrapilheira que ocorreu nesse período. A deposição via folhas foi de 27,29 kg P/ha/ano. Ferreira et al. (2007) encontraram deposição de 10,4 kg P/ha/ano. Fernandes et al (2006) encontraram 3,90 kg P/ha/ano em uma área de plantio de sabiá destinada a avaliação de serrapilheira, situada no município de Seropédica, Rio de Janeiro. De acordo com Fassbender (1985), taxas de transferência de fósforo com os resíduos vegetais oscilam entre 2 e $14 \mathrm{~kg} / \mathrm{ha} / \mathrm{ano}$ e, em floresta tropical, o equilíbrio de fósforo no sistema se mantém graças ao P inorgânicos e orgânicos lábeis, assim como o que está retido na biomassa, representando as formas mais facilmente disponíveis para a absorção pelas plantas. Tanto para deposição de nitrogênio como fósforo, as folhas foram os maiores contribuintes na serrapilheira, resultados semelhantes aos encontrados por Ferreira et al. (2007), que relataram que essa deposição é significativa para melhoria da fertilidade do solo.

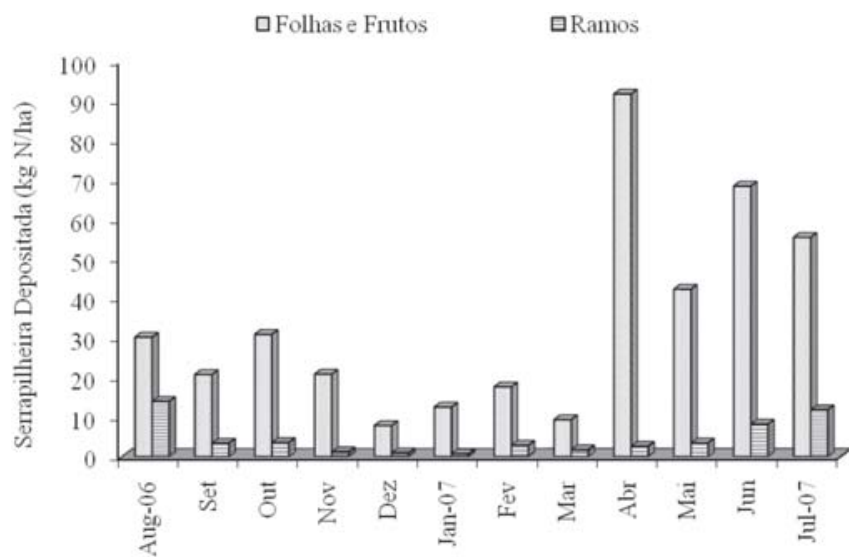

Total folhas e frutos $=408,05 \mathrm{~kg} \mathrm{~N} / \mathrm{ha}$

Total ramos $=54,63 \mathrm{~kg} \mathrm{~N} / \mathrm{ha}$

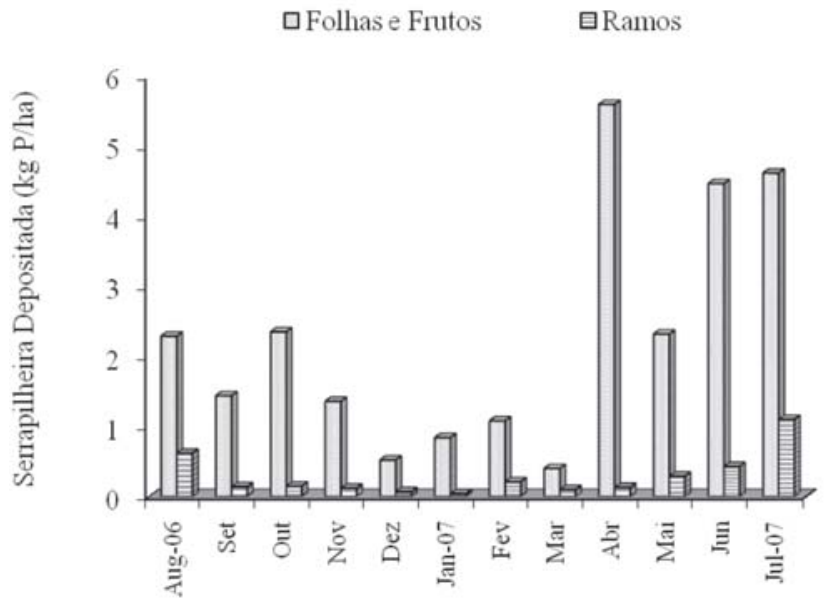

Total folhas e frutos $=27,29 \mathrm{~kg} \mathrm{P} / \mathrm{ha}$

Total ramos $=3,40 \mathrm{~kg} \mathrm{P} / \mathrm{ha}$

Figura 6 - Deposição de nitrogênio e fósforo (kg/ha) via folhas, frutos e ramos de serrapilheira.

A relação carbono/nitrogênio das folhas de serrapilheira depositada foi menor que 20 e, a dos ramos, entre 30 e 40 (Figura 7), comprovando a menor qualidade dos ramos. De acordo com Siqueira \& Franco (1988), quando a serrapilheira apresenta relação carbono/nitrogênio superior a 30:1, o nitrogênio fica imobilizado e, como consequência, ocorre redução na disponibilidade de $\mathrm{N}-\mathrm{NH}_{4}{ }^{+}$(amônio) e $\mathrm{N}^{-\mathrm{NO}_{3}}{ }_{3}^{-}$ (nitrato) no solo. Quando a relação fica entre 20 e 30:1, os processos de imobilização e mineralização se igualam e, abaixo de 20:1, ocorre a mineralização com a maior disponibilidade de compostos nitrogenados.

Segundo Bonito et al (2003), a vegetação em sítios ricos em nitrogênio produz serrapilheira com altos teores de decomposição da matéria orgânica do solo e mineralização de nitrogênio. Em ecossistemas pobres em nitrogênio, as plantas crescem mais vagarosamente e usam o nitrogênio de forma mais eficiente, produzindo serrapilheira de pior 
Folhas e Frutos

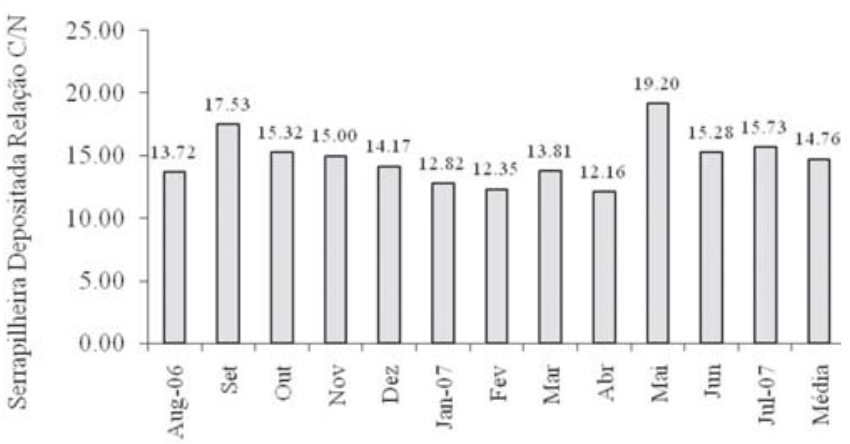

Média $=14,76 \mathrm{C} / \mathrm{N}$

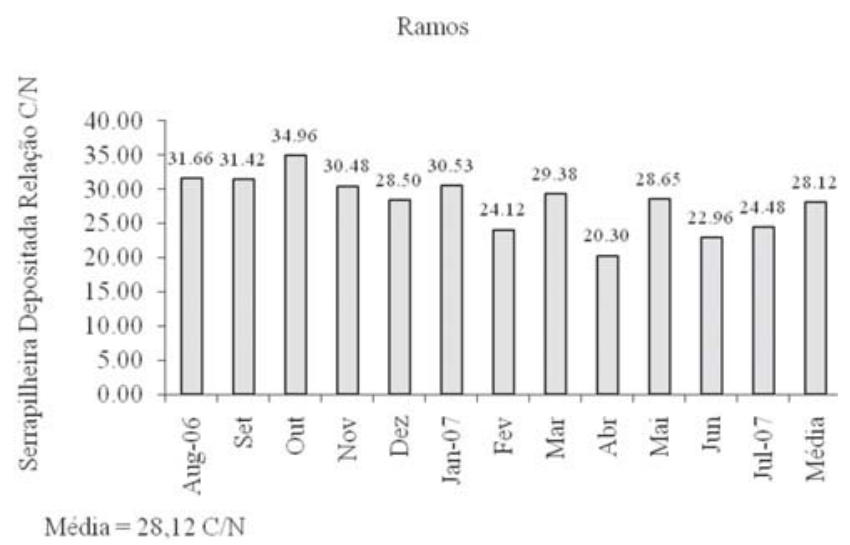

Figura 7 - Relação carbono/nitrogênio de folhas, frutos e ramos em serrapilheira em um bosque de sabiá.

qualidade. Em sítios pobres em nitrogênio, não somente a decomposição émais lenta como também é menor a proporção de nitrogênio da serrapilheira que é mineralizada e removida. Quando a relação carbono/nitrogênio é baixa, os organismos decompositores não são limitados pelo nitrogênio, o que resulta em liberação líquida de nitrogênio inorgânico para a solução do solo. A serrapilheira com alta relação carbono/ nitrogênio favorece a retenção de nitrogênio pelos organismos decompositores, o que reduz a disponibilidade de nitrogênio no solo.

\section{Conclusões}

A deposição de serrapilheira é uma importante via de retorno de nitrogênio e fósforo em bosque de sabiá na Zona da Mata, contribuindo para a manutenção desse ecossistema. A serrapilheira, de maneira geral, apresenta alta concentração de nitrogênio, sobretudo nas folhas, o que contribui para a reciclagem desse mineral no bosque. A concentração de fósforo na serrapilheira é relativamente baixa, mas importante no processo de reciclagem, em decorrência da maior disponibilidade usualmente encontrada no fósforo orgânico em comparação ao fósforo inorgânico. A serrapilheira é composta predominantemente por folhas, frutos e, em menor proporção, de ramos. A quantidade de serrapilheira depositada aumenta expressivamente no período de chuvas, com picos de deposição em períodos de veranico, ou seja, períodos secos dentro do período chuvoso, além de queda acentuada ao final do período chuvoso. Dessa forma, as maiores deposições de nutrientes via serrapilheira também ocorrem nesses períodos.

\section{Referências}

ANDRADE, A.G.; COSTA, G.S.; FARIAS S.M. Deposição e decomposição da serrapilheira em povoamentos de Mimosa caesalpiniifolia Benth, Acácia mangium e Acácia holosericea com quatro anos de idade em planosolo. Revista Brasileira de Ciência do Solo, v.34, n.4, p.777-785, 2000.

ARAUJO FILHO, J.A.; BARROS, N.N.; DIAS, M.L. et al, Desempenho de caprinos com alimentação exclusiva de Jurema Preta (Mimosa sp) e Sabiá (Mimosa caesalpiniifolia benth.) In: REUNIÃO ANUAL DA SOCIEDADE BRASILEIRA DE ZOOTECNIA, 27., 1990, Campinas. Anais... Campinas: Sociedade Brasileira de Zootecnia. 1990. p.68.

BEZERRA NETO, E.; BARRETO, L.P. Métodos de análises químicas em plantas. Recife: UFRPE, Imprensa Universitária, 2004. p.165.

BONITO, G.M.; COLEMAN, D.C.; HAINES, B.L et al. Can nitrogen budgets explain differences in soil nitrogen mineralization rates of forest stands along an elevation gradient forest ecology and management. Forest Ecology and Management, v.176, n.3, p.563-574, 2003.

BRAY, J.R.; GORHAM, E. Liter productions in Forest of the world. In: Advances in ecology research. [S.I.], 1964. p.101-157.

BRUCE, R.C.; EBERSOHN, J.P. Litter measurements in two grazed pastures in southeast Queensland. Tropical Grasslands, v.16, n.4, p.180-185. 1982.

CALDAS, G.G.; SANTOS, M.V.F.; FERREIRA, R.L.C. et al. Efeito da fertilização fosfatada na produção de raízes, liteira e nodulação de Mimosa caesalpiniifolia Benth. Revista Árvore, v.33, n.2, p, 237-244, 2009.

COMPANHIA PERNAMBUCANA DO MEIO AMBIENTE - CPRH. Diagnóstico sócio ambiental do litoral norte de Pernambuco. Recife 2003. p.214.

DAMES, J.F.; SCHOLES, M.C.; STRAKER, C.J. Nutrient cycling in a Pinus patula plantation in the Mpumalanga Province, South Africa. Applied Soil Ecology, v.20, n.3, p.211-226, 2002.

DRUMOND, M.A. Estratégias para o uso sustentável da biodiversidade da Caatinga. Petrolina, PE: [s.n.], 2000. 21p. Não publicado. Documento para discussão no Grupo de Trabalho Estratégias para o uso sustentavel, no Seminário Biodiversidade da Caatinga, realizado em Petrolina, PE, 2000.

DRUMOND, A.M.; OLIVEIRA, V.R. Produção massal de sabiá (Mimosa caesalpiniifolia benth) sem acúleos. Petrolina: EMBRAPA/CPTSA, 1989. 1p. (Boletim de Pesquisa em Andamento, 59).

DUBEUX JR., J.C.B.; SOLLENBERGER, L.E.; VENDRAMINI, J.M.B. et al. Litter mass, deposition rate, and chemical composition in grazed Pensacola bahiagrass pastures managed at different intensities. Crop Science, v.46, n.4, p.1299-1304, 2006a.

DUBEUX JR., J.C.B.; SOLLENGERGER, L.E.; COMERFORD, N.B. et al. Management intensity affects density fractions of soil organic matter from grazed bahiagrass swards. Soil Biology e Biochemistry, v.38, n.9, p.2705-2711, 2006b. 
EMPRESA BRASILEIRA DE PESQUISA AGROPECUÁRIA EMBRAPA. Centro Nacional de Pesquisa de solo. Manual de métodos de análises de solo. Rio de Janeiro: CNPS, 1997. 212p.

FASSBENDER, H.W. Ciclos da matéria orgânica e dos nutrientes em ecossistemas florestais dos trópicos. In: REUNIÃO BRASILEIRA DE FERTILIDADE DO SOLO $>$ RECICLAGEM DE NUTRIENTES E AGRICULTURA DE BAIXOS INSUMOS NOS TRÓPICOS, 16., 1985, Ilhéus. Anais... Ilhéus: CEPLAC, 1985.

FERREIRA, R.L.C.; LIRA JR., M.A; ROCHA, M.S. et al. Deposição e acumulo de matéria seca e nutrientes em serrapilheira em um bosque de sabiá (Mimosa caesalpiniifolia Benth). Revista Árvore, v.31, n.1, p.7-12, 2007.

FERNANDES, M.M.; PEREIRA, M.G.; MAGALHAES, L.M.S. et al. Aporte e decomposição de serrapilheira em áreas de floresta secundária, plantio de sabiá (Mimosa caesalpiniaefolia Benth.) e andiroba (Carapa guianensis Aubl.) na flora Mário Xavier, RJ. Ciência Florestal, v.16, n.2, p.163-175, 2006.

GARCIA, R.; OBEID, J.A.; COLEHO DA SILVA, J.F. et al. Consumo e digestibilidade aparente de feno de capim gordura (Melinis minutiflora, Pal. De Beauv) produzido sob diferentes métodos de fenação. Revista da Sociedade Brasileira de Zootecnia, v.20, n.2, p.29, 1991.

JACOMINE, P.K.T. Evolução do conhecimento sobre solos coesos no Brasil. In: WORKSHOP COESÃO EM SOLOS DOS TABUleiros COSTEIROS, 20., 2002, Aracajú. Anais... Aracaju: Embrapa Tabuleiros Costeiros, 2001. p.19-46.

LEDGARD, S.F.; STEEL, K.W.; Biological nitrogen fixation in mixed legume/grass pastures. Plant and Soil, v.141, n.2, p.137-153, 1992.

LIMA, I.C.A.R.; LIRA, M.A.; MELLO, A.C.L. Avaliação de sabiazeiro (Mimosa caesalpiniaefolia Benth) quanto a acúleos e preferência por bovinos. Revista Brasileira de Ciências Agrárias, v.3, n.3, p.289-294, 2008.

LIMA, J.L.S. Reconhecimento de trinta espécies arbóreas e arbustivas da caatinga através da morfologia da casca.1982. 69f. Dissertação (Mestrado em Botânica) Universidade federal Rural de Pernambuco, Recife.

MEDEIROS, R.; ALMEIRA, S.S. Queda de serrapilheira e a exclusão de água numa floresta densa de terra firme da Estação Científica Ferreira Penna - ECFPn Caxiuanã, Município de Melgaço - PA: Estação Científica, 1993. 2p.

MENDES, B.V. Sabiá (Mimosa caesalpiniifolia Benth) valiosa forrageira arbórea e produtora de madeira das caatingas. Mossoró: ESAM, 1989. p.31. (ESAM Coleção Mossorroense, $660)$.
MONTEIRO, F.A.; WERNER, J.C. Reciclagem de nutrientes nas pastagens. In: SIMPÓSIO SOBRE O MANEJO DA PASTAGEM, 14., 1997, Piracicaba. Anais... Piracicaba: FEALQ, 1997. p.55-84.

MOURA, O.N.; PASSOS, M.A.A.; FERREIRA, R.L.C. et aL. Distribuição de biomassa e nutrientes na parte aérea de Mimosa caesalpiniifolia Benth. Revista Árvore, v.30, n.6, p.877-884, 2006.

OLIVEIRA, J.G.B.; PRISCO, J.T. Transpiração e balanço hídrico de plantas da caatinga. Boletim da Sociedade Cearense de Agronomia, p.41-46, 1967.

PEREIRA, V.A.L.; SILVA, M.V.; LIRA, M. et al. Composição químico-bromatologica das sobras do "mulch" e feno de sabiá (Mimosa caesalpinifolia benth.), sem e com acúleos. Revista Pasturas Tropicalis, v.23, n.2, p.16-19, 1997.

REIS, M.G.F., BARROS, N.F. Ciclagem de nutrientes em plantios de eucaliptos. In: BARROS,N. F.; NOVAIS, R.F. (Eds.) Relação solo - eucalipto. Viçosa, MG: Folha de Viçosa, 1990. p.265-302.

SAMPAIO, E.V.S.B.; NUNES, K.S.; LEMOS, E.E.P. Ciclagem de nutrientes na mata de Dois Irmãos (Recife-PE) através da queda de material vegetal. Pesquisa Agropecuária Brasileira, v.23, n.10, p.1055-1061, 1988.

SAMPAIO, F.A.R.; FONTES, L.E.F.; COSTA, L.M. et al. Balanço de nutrientes e da fitomassa em um argissolo amarelo sob floresta tropical amazônica após a queima e cultivo com arroz. Revista Brasileira de Ciências do Solo, v.27, n.6, p.1611170, 2003.

SILVA, D.J.; QUEIROZ, A.C. Analise de alimentos: métodos químicos e biológicos. 3.ed. Viçosa, MG: Universidade Federal de Viçosa, 2002. p.235.

SIQUEIRA, J.O.; FRANCO, A.A. Biotecnologia do solo: fundamentos e perspectivas. Lavras: ESAL/FAEP, 1988. 235p.

TIESSEN, H.; MENEZES, R.S.C.; SALCEDO, I.H. et al. Organic matter transformations and soil fertility in a treed pasture in semiarid NE Brazil. Plant and Soil, v.252, p.195-205, 2003.

TIGRE, G.B. Silvicultura para as matas xerófilas. Fortaleza: Departamento Nacional de Obras Contra a Secas - DNOS, 1986. p.151-154. (Publicação, 25).

VIRGINIO FILHO, E. Aspectos ambientais do seminário sociedade e ecologia, In: SEMINÁRIO NORDESTINO SOBRE A CAATINGA, 1., 1995, João Pessoa. Anais... João Pessoa, 1995. p.67-69.

TAUK, S.M. Biodegradação de resíduos orgânicos do solo. Revista Brasileira de Geociência, v.20, n.1, p.299-301, 1990. 